FEMS Microbiology Ecology 27 (1998) 339-350

\title{
Community analysis of ammonia-oxidising bacteria, in relation to oxygen availability in soils and root-oxygenated sediments, using PCR, DGGE and oligonucleotide probe hybridisation
}

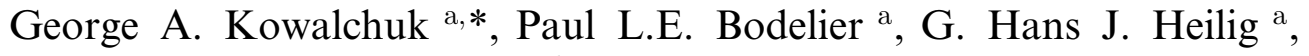 \\ John R. Stephen ${ }^{b}$, Hendrikus J. Laanbroek ${ }^{\mathrm{c}}$ \\ ${ }^{a}$ Department of Plant-Microorganism Interactions, Netherlands Institute of Ecology, Centre for Terrestrial Ecology, Boterhoeksestraat 22, \\ P.O. Box 40, 6666 ZG Heteren, The Netherlands \\ ${ }^{\mathrm{b}}$ Department of Molecular and Cell Biology, Institute of Medical Sciences, University of Aberdeen, Foresterhill, Aberdeen AB25 $2 Z D$, UK \\ ${ }^{c}$ Department of Microbial Ecology, Netherlands Institute of Ecology, Centre for Limnology, Rijksstraatweg 6, 3631 AC Nieuwersluis,
} The Netherlands

Received 18 March 1998; received in revised form 17 July 1998; accepted 27 July 1998

\begin{abstract}
The rhizosphere of oxygen-releasing wetland plants provides a niche for oxygen-consuming microorganisms such as chemolithotrophic ammonia-oxidising bacteria. These bacteria are adapted to oxygen limitation with respect to their affinity for oxygen, ability to survive periods of anoxia, and immediate response to the appearance of oxygen. In this study the techniques of specific amplification of ammonia oxidiser 16S rDNA fragments by PCR, separation of mixed PCR samples by denaturing gradient gel electrophoresis (DGGE), and band identification by specific hybridisation with oligonucleotide probes were combined to allow for the comparison of the community composition of multiple samples over space and time. DGGE bands of interest were also excised for DNA isolation, reamplification, sequence determination and phylogenetic analysis. We compared monthly samples from both the root zone and the bare sediment of a shallow lake inhabited by the emergent macrophyte Glyceria maxima to determine the seasonal effects that the plant roots and the oxygen availability might have on the $\beta$-subgroup ammonia-oxidiser populations present. Similarly, five soil or sediment samples, varying in oxygen availability, from different locations in the Netherlands were compared. Although the presence of two previously defined Nitrosospira sequence clusters could be differentially detected in the samples examined, there was no evidence for a particular group which was specific to periodically anoxic environments. (c) 1998 Federation of European Microbiological Societies. Published by Elsevier Science B.V. All rights reserved.
\end{abstract}

Keywords: Nitrosospira; Nitrosomonas; Diversity; Nitrification; Biogeography; Oxygen limitation

\footnotetext{
* Corresponding author. Tel.: +31 (26) 479 1314; Fax: +31 (26) 472 3227; E-mail: gkowal@cto.nioo.knaw.nl
}

\section{Introduction}

Plants rooting in flooded soils and sediments contain aerenchymatous tissue in their shoots and roots. This airspace continuum facilitates the movement of 
atmospheric or photosynthetic oxygen to the roots [1-3]. Thus, root respiration continues, and the accumulation of reduced phytotoxic compounds (i.e. $\left.\mathrm{Fe}^{2+}, \mathrm{Mn}^{2+}, \mathrm{S}^{2-}\right)$ is prevented by radial oxygen loss into the surrounding soil or sediment. The plant-released oxygen can be used by a vast number of chemical as well as biological processes. One of these processes is the conversion of ammonia into nitrate by nitrifying bacteria. Since this process cannot proceed in the absence of oxygen, oxygen-releasing plants can have a major impact on nitrogen cycling in otherwise anoxic soil or sediment layers. The plant-induced nitrate production can subsequently lead to enhanced denitrification, thus elevating nitrogen loss from the ecosystem.

Stimulation of nitrification by oxygen-releasing plants has been demonstrated indirectly by most probable number (MPN) counts [4,5], activity measurements $[4,6,7]$ and evolution of ${ }^{15} \mathrm{~N}_{2}$ following addition of ${ }^{15} \mathrm{NH}_{4}^{+}$to microcosms planted with rice [8]. The study of Bodelier et al. [4] showed higher numbers and potential activities of both ammonia- and nitrite-oxidising bacteria in the root zone of the emergent macrophyte Glyceria maxima (Hartm.) Holmb. at a freshwater lake location in the Netherlands. This stimulation only occurred in spring and early summer and disappeared later in the growing season, probably due to plant-induced ammonia limitation. Furthermore, comparison of the oxygen consumption kinetics of the lake sediment ammonia oxidisers with those from a permanently oxic dune soil and two predominantly oxic grassland soils revealed possible adaptations of the ammonia-oxidising bacteria from the lake sediment to sub-oxic or anoxic habitats.

The seasonal dynamics and adaptations of the ammonia oxidisers might be reflected by shifts in community composition in concert with the presence or absence of key regulatory substrates such as oxygen and ammonia. However, pure culture isolation would be an imperative step in addressing directly the physiological differences between nitrifying bacteria occurring under different environmental conditions. Unfortunately, this task has proven extremely difficult and tedious for this group of microorganisms, and present culture techniques seem to isolate specifically only a small fraction of the total diversity within the chemolithotrophic ammonia-oxidising bacteria [9-11].

The recent application of molecular biological techniques targeting the $16 \mathrm{~S}$ rRNA molecule to microbial ecology has provided a valuable addition to extant culture-based methods for studying the diversity, composition, and dynamics of microbial communities [12-14]. The ammonia-oxidising bacteria of the $\beta$-subgroup Proteobacteria represent ideal candidates for analysis via a $16 \mathrm{~S}$ rDNA-based approach as they comprise a monophyletic group based upon 16S rDNA sequence comparisons, and their laboratory cultivation has proven difficult, time-consuming, and biased for the strains most amenable to the enrichment conditions used $[10,15,16]$. A number of recent studies have exploited various 16S rDNAbased strategies to study nitrifiers in several natural habitats $[9,11,17-19]$ as well as in sewage treatment plants [20-22] and fish culture aquaria [23]. Through the sequence analysis of cloned 16S rDNA fragments, Stephen et al. [11] revealed that the $\beta$-subgroup ammonia-oxidising bacteria comprise at least seven phylogenetically distinguishable sequence clusters within the Nitrosomonas and Nitrosospira genera (the latter encompassing the previous genus designations Nitrosolobus and Nitrosovibrio [15]) (Fig. 1).

Denaturing gradient gel electrophoresis (DGGE) offers an alternative to tedious and expensive cloning-based approaches by separating the constituent sequences of complex mixtures of PCR products based upon their differential mobility in an acrylamide gel with a gradient of denaturing chemicals [24]. This technique has been adapted for microbial ecological studies by Muyzer et al. [25], and has been applied to the study of $\beta$-subgroup ammonia-oxidising communities in coastal sand dune soils by Kowalchuk et al. [18]. This latter study also demonstrated that the DGGE pattern alone was not sufficient to infer sequence cluster affinity or ascertain the identity of co-migrating fragments. It is, however, possible to interpret DGGE patterns more rapidly by the use of oligonucleotide probes targeting signature sequences contained within PCR products derived from organisms of interest [26,27], and a hierarchical set of hybridisation probes for $\beta$ subgroup ammonia oxidisers has recently been designed [28]. 
Previous molecular studies of $\beta$-subgroup ammonia oxidisers have shown that specific sequence clusters are associated with certain environments and that shifts in environmental factors such as $\mathrm{pH}$ and ammonia concentration can affect the sequence cluster composition of the ammonia-oxidising community $[11,18,28,29]$. The aim of this study was to investigate whether the seasonal dynamics and adaptations of the ammonia-oxidising community in the root zone of G. maxima, as was found by Bodelier et al. [4], are reflected in the sequence cluster composition of these communities. Therefore, the same sediment and soil samples were analysed using the PCR, DGGE and hybridisation approach outlined above. Where hybridisation results failed to fully resolve DGGE patterns or where DGGE patterns and hybridisation results were in apparent conflict, DGGE bands were excised for subsequent sequence determination and phylogenetic analysis.

\section{Materials and methods}

\subsection{Sampling of sediment and soil}

As described by Bodelier et al. [4], sediment samples were collected inside and outside the root zone of the emergent macrophyte Glyceria maxima (Hartm.) Holmb. (reed sweet grass) at Lake Drontermeer, near the township of Elburg $\left(52^{\circ} 58^{\prime} \mathrm{N}, 5^{\circ} 50^{\prime} \mathrm{E}\right)$ (the Netherlands), in the period from May 1994 to May 1995. Sample sites within the vegetation have shown $100 \%$ dominance of $G$. maxima for at least 10 years. The influence of plant-derived oxygen on the soil environment in these locations has been demonstrated previously by year-round redox potential measurements, which show seasonal fluctuations in the root zone, but not in the bare sediment [4]. Five intact cores ( $25 \mathrm{~cm}$ in depth, $10 \mathrm{~cm}$ in diameter) were taken per sampling event, and the top $5 \mathrm{~cm}$ were excluded from all analyses. The sediment samples from the root zone of G. maxima collected in May 1995 were compared to soil samples from three other locations differing in their oxicity profiles: (1) a coastal dune top (Meijendel, near The Hague, the Netherlands) $\left(52^{\circ} 08^{\prime} \mathrm{N}, 4^{\circ} 19^{\prime} \mathrm{E}\right)$ whose loose, sandy soil matrix provides permanently oxic conditions, (2) a chalk grassland soil with high moisture and loess contents in the Gerendal nature reserve $\left(50^{\circ} 5^{\prime} \mathrm{N}\right.$, $5^{\circ} 54^{\prime} \mathrm{E}$; 22 years out of production) in the south of the Netherlands, where high denitrification rates (results not shown) indicate the presence of anoxic microsites, and (3) a calcareous grassland soil from a river levee near the village of Brummen, the Netherlands $\left(52^{\circ} 5^{\prime} \mathrm{N}, 6^{\circ} 9^{\prime} \mathrm{E}\right)$ that is periodically anoxic due to seasonal flooding. Five samples were collected per location, and each sample consisted of 32 cores $(5 \mathrm{~cm}$ in depth, $2.5 \mathrm{~cm}$ in diameter). Further descriptions of the sampled locations, sampling methods, and soil characteristics can be found in Bodelier et al. [4].

\subsection{DNA isolation}

DNA from sediment and soil samples was isolated by a modified protocol of Stephen et al. [11]. Sediment or soil samples ( $0.5 \mathrm{~g}$ wet weight), $0.5 \mathrm{ml}$ extraction buffer $\left(120 \mathrm{mM} \mathrm{K}_{2} \mathrm{HPO}_{4}[\mathrm{pH} 8] ; 5 \%\right.$ hexadecyltrimethylammoniumbromide (CTAB), Sigma), $0.5 \mathrm{~g}$ glass beads $(0.1 \mathrm{~mm}$, BioSpec Products, Technolab, Alkmaar, the Netherlands) and $0.5 \mathrm{ml}$ phenol/ chloroform/isoamyl alcohol (25:24:1 v/v, Sigma) were mixed in a 2-ml destruction tube (Anthos Labtec, Heerhugowaard, the Netherlands).

Samples were shaken three times at $5000 \mathrm{rpm}$ for $30 \mathrm{~s}$ in a mini-bead beater (BioSpec). The tubes were cooled on ice between shaking periods. After centrifugation $(5 \mathrm{~min}, 3000 \times \mathrm{g}$ ), $300 \mu \mathrm{l}$ of the aqueous phase was removed and the rest of the tube's contents re-extracted with an additional $300 \mu$ extraction buffer. The two resulting aqueous phases were pooled and twice extracted with 1 volume of chloroform/isoamyl alcohol $(24: 1 \mathrm{v} / \mathrm{v})$. After centrifugation, the DNA was precipitated for at least $1 \mathrm{~h}$ at $-20^{\circ} \mathrm{C}$ with 0.1 volume $3 \mathrm{M} \mathrm{CH}_{3} \mathrm{COONa}[\mathrm{pH}$ 5.2] and 1 volume of isopropanol. Centrifugation (15 min, $14000 \times g$ ) resulted in a pellet which was subsequently washed with $70 \%$ ice-cold ethanol. Pellets were allowed to air dry, and DNA was resuspended in $40 \mu 1 \mathrm{TE}$ buffer (10 mM Tris; $0.1 \mathrm{mM}$ EDTA [pH 8.5]) and $10 \mu$ loading dye. To remove humic compounds, DNA was loaded on a $1 \%$ agarose: $1 \%$ polyvinylpolypyrrolidone (PVPP) composite gel $(0.5 \times \mathrm{TBE} ; 1 \times \mathrm{TBE}=90 \mathrm{mM}$ Tris-borate, $2 \mathrm{mM}$ EDTA, pH 8.3) as described by Kowalchuk et al. [18] and run at $100 \mathrm{~V}$ for $2 \mathrm{~h}$. 
DNA longer than $10 \mathrm{~kb}$ was excised and isolated from the agarose using the QIAquick gel extraction kit (Qiagen, Chatsworth, CA, USA), and DNA was eluted with $50 \mu 10 \mathrm{mM}$ Tris ( $\mathrm{pH}$ 8.5).

\subsection{PCR conditions}

PCR was first performed using 10-100 ng template DNA with the Eubacterial primers pA and pH [30] using Tbr polymerase ('Dynazyme'; Finnzymes; Iploo, Finland) according to the manufacturer's recommendations with the following thermocycling program: $1 \times\left(2 \mathrm{~min}, 94^{\circ} \mathrm{C}\right), 30 \times\left(30 \mathrm{~s}, 94^{\circ} \mathrm{C} ; 60 \mathrm{~s}\right.$, $55^{\circ} \mathrm{C}$ and $75 \mathrm{~s},+1$ s/cycle, $\left.72^{\circ} \mathrm{C}\right)$ and $1 \times(5 \mathrm{~min}$, $72^{\circ} \mathrm{C}$ ) with a reaction volume of $25 \mu 1$. PCR products (all $25 \mu \mathrm{l}$ ) were examined by electrophoresis in a $0.5 \times \mathrm{TBE} 1 \%$ low-melting point agarose gel (LMMP agarose; Boehringer, Mannheim, Germany) followed by ethidium bromide staining. For all samples, the product of the expected size $(1.5 \mathrm{~kb})$ was excised from the gel (total of $100 \mathrm{mg}$ gel material). The gel fragment was melted by heating for $5 \mathrm{~min}$ at $65^{\circ} \mathrm{C}$, and $1 \mu \mathrm{l}$ was used as template in a second PCR using the CTO primers (CTOf189-GC, CTO654r), previously described to amplify specifically a 465-bp fragment of the 16S rRNA gene from $\beta$-Proteobacteria ammonia-oxidising bacteria [18] with the addition of a 5' GC-clamp [31]. These 50- $\mu 1$ reactions were performed using Expand High Fidelity polymerase (Boehringer, Mannheim) according to the manufacturer's specifications using the following thermocycling program: $1 \times\left(1 \mathrm{~min}, 94^{\circ} \mathrm{C}\right), 25 \times(30 \mathrm{~s}$, $92^{\circ} \mathrm{C} ; 60 \mathrm{~s}, 57^{\circ} \mathrm{C}$ and $45 \mathrm{~s},+1$ s/cycle, $68^{\circ} \mathrm{C}$ ) and $1 \times\left(5 \mathrm{~min}, 68^{\circ} \mathrm{C}\right)$. PCR amplification from plasmid controls was performed by direct use of the CTO primers using the conditions described above except that $5 \mathrm{ng}$ of DNA was used as template and reaction volumes were $25 \mu \mathrm{l}$. All reactions were overlaid with an equal volume of mineral oil (Sigma, molecular biology grade) and run on an OmniGene Thermal Cycler (Hybaid, Teddington, UK). Final PCR products were examined by agarose gel electrophoresis $(1.5 \%$ agarose, $0.5 \times \mathrm{TBE})$ and stained with ethidium bromide for visualisation upon UV illumination.

\subsection{DGGE, blotting and oligonucleotide hybridisation}

PCR products recovered with the CTO primers were subjected to DGGE according to the protocol of Muyzer et al. [32] as adapted by Kowalchuk et al. [18] for the study of ammonia-oxidising bacteria. Gels contained a $38-50 \%$ gradient of denaturing chemicals with $100 \%$ denaturant defined as $7 \mathrm{M}$ urea and 40\% formamide. DNA was visualised after ethidium bromide staining by UV transillumination, and gel images were stored using 'The Imager' system (Ampligene; Illkirch, France).

DNA in the polyacrylamide gels was blotted to Hybond-N ${ }^{+}$Nucleic Acid Transfer Membranes (Amersham, UK), using a Transblot SD (Bio-Rad) according to Muyzer et al. [32]. After completion of the transfer, the DNA was denatured (DNA-side down) on Whatman 3MM (Whatman) filter paper soaked with $0.4 \mathrm{M} \mathrm{NaOH} ; 0.6 \mathrm{M} \mathrm{NaCl}$ and similarly neutralised with $1 \mathrm{M} \mathrm{NaCl} ; 0.5 \mathrm{M}$ Tris $(\mathrm{pH}$ 8). Membranes were sealed in plastic and stored at $4^{\circ} \mathrm{C}$ until further use. Hybridisation analyses were conducted using the oligonucleotide probes and hybridisation conditions described by Stephen et al. [28]. Specifically, the probes $\beta$-Ammo 223r, Nsp436r, Nmonas244r, NspCl3-455r and NspCl4$446 \mathrm{r}$ were used to detect 16S rDNA fragments from all $\beta$-subgroup ammonia oxidisers, Nitrosospira, Nitrosomonas, cluster 3 Nitrosospira and cluster 4 Nitrosospira, respectively. No attempts to quantify the intensity of radioactive signals were made during the course of this study.

\subsection{Sequence analysis of bands excised from $D G G E$ gels}

Bands chosen for sequence analysis were carefully excised from the DGGE gel with a scalpel. Only the centre-most $50 \%$ of each band was excised in order to avoid the lane edges where smearing was observed. DNA extraction, reamplification and DNA sequencing were as described by Kowalchuk et al. [18]. DNA sequence manipulations were performed using the SeqApp program, version 1.9a169 [33], and phylogenetic analyses were implemented through PHYLIP 5.57 [34]. Distance matrix analyses were according to the method of Jukes and Cantor [35] with a masking function to exclude ambiguous data, and phylogenetic tree construction was by neighbour joining [36]. Phylogenetic analysis was performed for 287 positions which could be unambiguously aligned 
for all sequences used in the analysis. Bootstrapping was conducted with 100 replicates using the program SeqBoot [34]. Bootstrap supports for the sequence clusters were similar to those found previously [11]. Recovered sequences were also tested for homology to known sequences in the EMBL databank using the FastA program [37].

All unique sequences have been deposited in the EMBL database under the accession numbers AJ000271-AJ000280. Bands whose nucleotide sequences were determined have been given labels in Figs. 2 and 3 which correspond to the sequence names beginning with a ' $\mathrm{B}$ ' in Fig. 1 . The addition of an asterisk to a band label (Figs. 2 and 3) indicates a difference of one base pair from the given numbered sequence. These differences have been shown to be introduced at the ambiguous position of the reverse primer by PCR [18] and have not been included in the phylogenetic analysis.

\section{Results}

\subsection{Recovery of ammonia-oxidiser $16 \mathrm{~S}$ rDNA fragments from sediment and soil samples}

Attempts to recover PCR products from direct amplification with the CTO primer pair, as described in Kowalchuk et al. [18], were not consistently successful for all samples, probably due to the inhibitory effect of some co-purified humic substances (results not shown). However, after employment of a nested PCR strategy in which DNA extracted from soil is first amplified with Eubacterial primers prior to specific amplification with the CTO primers, $\beta$-subgroup ammonia oxidisers could be detected from all sediment and soil samples analysed. For consistency, all DGGE and hybridisation analyses were therefore conducted using the nested PCR protocol. The detection of $\beta$-subgroup ammonia oxidisers is in agreement with previous reports of detectable levels of chemolithotrophic ammonia oxidation for all the sites, and all sampling dates examined [4]. Thus, the nested PCR strategy employed was able to detect less than $10^{3}$ culturable cells $\mathrm{g}^{-1}$ dry sediment, as determined previously by MPN analysis [4].

\subsection{DGGE and hybridisation analysis of Drontermeer sediment samples}

Nested PCR products recovered from the monthly $G$. maxima root zone and bare sediment samples from Lake Drontermeer were subjected to DGGE analysis along with control fragments derived from cloned sequences of known cluster affinity (Fig. 2) [11]. Fragment mobilities from environmental samples ranged from 44.5 to $47.2 \%$ denaturant, whereas control ammonia-oxidiser fragment mobilities ranged from 43.0 to $47.0 \%$ denaturant concentration. DGGE patterns from environmental samples were quite simple with usually between two and six detectable bands per sample. In both control and environmental DGGE patterns, bands often occurred in doublets, which is consistent with previous results which showed that a single template sequence can give rise to multiple DGGE bands due to an ambiguous position in the CTO reverse primer [18]. Most samples, except the root zone sample from June 1994 and the bare sediment sample from July 1994, displayed a clear double band at approximately $45 \%$ denaturant. Another doublet at approximately 46\% denaturant could be observed in many samples although its relative intensity was quite variable. These two doublets correspond well to the band positions of Nitrosospira clusters 2 or 3 and cluster 4 controls, respectively. There were no apparent trends in banding patterns with respect to observed seasonal differences in ammonia oxidiser numbers and potential nitrification activities [4]. There were also no consistent differences detected between the DGGE patterns from root zone versus bare sediment samples. Both types of samples gave similar results in the months of August and September 1994 and March-May 1995, whereas other sampling months produced clear differences between the two zones.

In order to determine the sequence cluster affinities of the detected DNA fragments, hybridisation analysis was performed using both the genus- and cluster-specific probes described by Stephen et al. [28]. All bands, except the lower doublet in the June 1994 root zone sample and the lowest band in the July 1994 bare sediment sample, showed positive hybridisation with the Nitrosospira-specific probe. The $\mathrm{Ni}$ trosospira-negative bands also failed to hybridise with the probe designed to detect all $\beta$-subgroup 


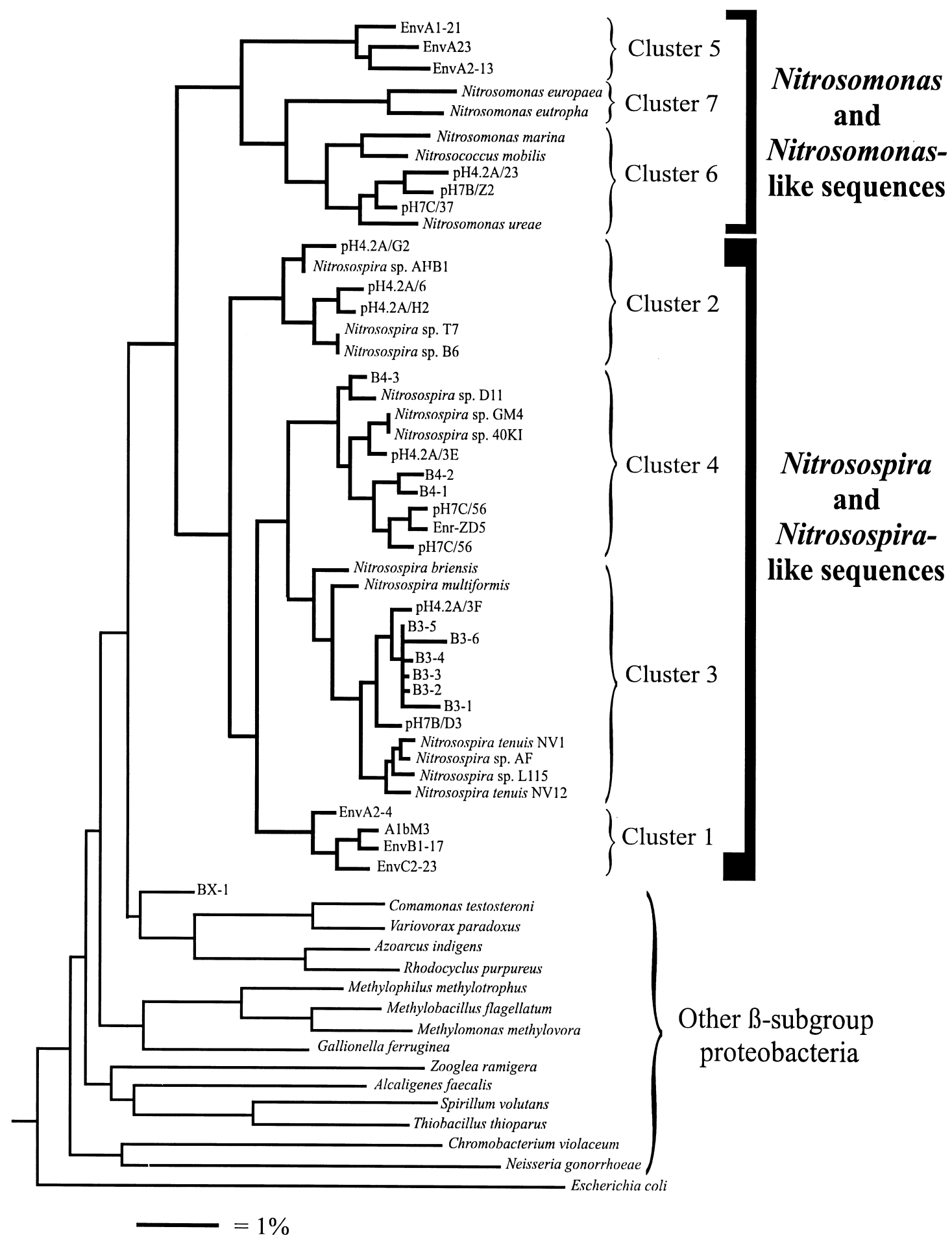


Fig. 1. Neighbour-joining tree based upon partial 16S rDNA sequences from $\beta$-subgroup ammonia oxidisers. Sequence analysis is as described in the text using the cluster designations of Stephen et al. [11]. Sequences derived from DGGE bands recovered from soil and sediment samples, designated with a 'B', correspond to the labeled bands in Figs. 2 and 3. Sequence names beginning with 'pH' or 'Env' refer to clones derived from environmental samples from soil (of the $\mathrm{pH}$ indicated) and from marine sediment respectively. Sequence A1bM3 is derived from a marine sediment enrichment culture [11]. Nitrosospira isolates 40KI, AF, B6, D11, GM4, L115 and T7 were purified from sewage or soil [49].

$\leftarrow$

ammonia oxidisers. All Nitrosospira-like bands could be further classified by hybridisation analysis into either Nitrosospira clusters 3 or 4 , and labels to the left of the bands in Fig. 2 indicate predicted cluster affinity. Neither DGGE banding pattern nor hybridisation results indicated the recovery of detectable amounts of Nitrosomonas-like rDNA sequences.

Hybridisation results clearly demonstrated that similar DGGE mobilities were not predictive of common sequence cluster affinities, as was previously demonstrated with known control sequences by Kowalchuk et al. [18]. For example, the July 1994 root zone sample contains bands which align well with the control for Nitrosospira cluster 3, but hybridisation analysis identified all bands in this sample as belonging to Nitrosospira cluster 4. Likewise, the bare sediment samples from June and May 1994 and the root zone sample from November 1995 all contain bands that co-migrate with the Nitrosospira cluster 4 control, yet are identified as belonging to Nitrosospira cluster 3 by hybridisation.

\subsection{DGGE and hybridisation analysis of soil and sediment samples with different oxicity profiles}

PCR products recovered from five different soil/ sediment types were also examined by DGGE (Fig. 3). All samples gave very similar DGGE patterns with all bands within the range of $44.5-46.5 \%$ denaturant. The dominant feature of all DGGE patterns was a doublet at approximately $45 \%$ denaturant, although some samples contained other bands lower in the gel. All bands reacted positively with the $\mathrm{Ni}$ trosospira-specific probe, and there were no Nitrosomonas-like sequences detected.

As with the Drontermeer samples, hybridisation analysis revealed the presence of only Nitrosospira clusters 3 and 4 among the ammonia oxidiser sequences detected. Although DGGE banding patterns were quite similar for the five locations examined, the distribution of these two sequence clusters clearly differed, as denoted by the sequence cluster designations given in Fig. 3. This is exemplified by the top

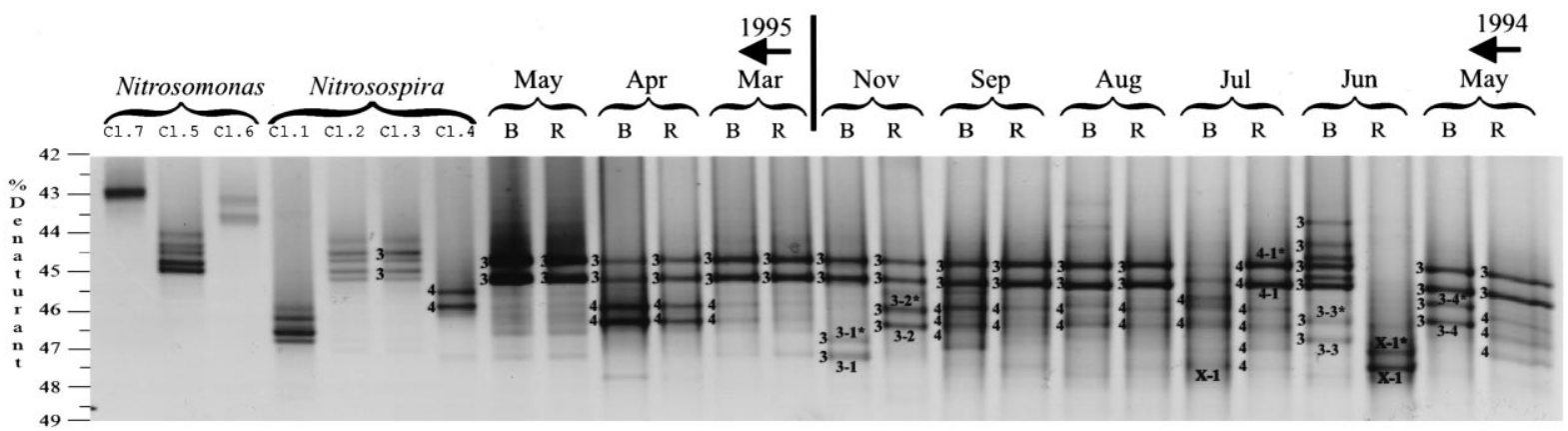

Fig. 2. DGGE of Lake Drontermeer monthly samples. DGGE analysis is of PCR products obtained from DNA of Lake Drontermeer monthly samples using the CTO primer set. Cloned sequences representing the seven previously defined sequence clusters of the $\beta$-subgroup ammonia oxidisers are also shown for comparison with environmental samples [11]. Reference clones were as follows: Nitrosomonas europaea ATCC 25978, Nitrosomonas, cluster 7; EnvA1-21, Nitrosomonas-like, cluster 5; pH4.2A/23, Nitrosomonas, cluster 6; EnvA2-4, Nitrosospira-like, cluster 1; pH4.2A/G2, Nitrosospira, cluster 2; pH4.2A/3F, Nitrosospira, cluster 3; pH4.2A/3E, Nitrosospira, cluster 4. Sediment samples are labeled 'B' and ' $\mathrm{R}$ ' for bare sediment and root zone, respectively. Bands with labels were excised for sequence analysis and their designations correspond to those found in Fig. 1. The first number in each label indicates the cluster designation, and bands having identical labels produced the same nucleotide sequences. Sequences which are labeled with an asterisk have a 1-bp difference (T for C) with their namesake bands at position 647 (Escherichia coli numbering [50]) introduced by the ambiguity in the reverse primer. 


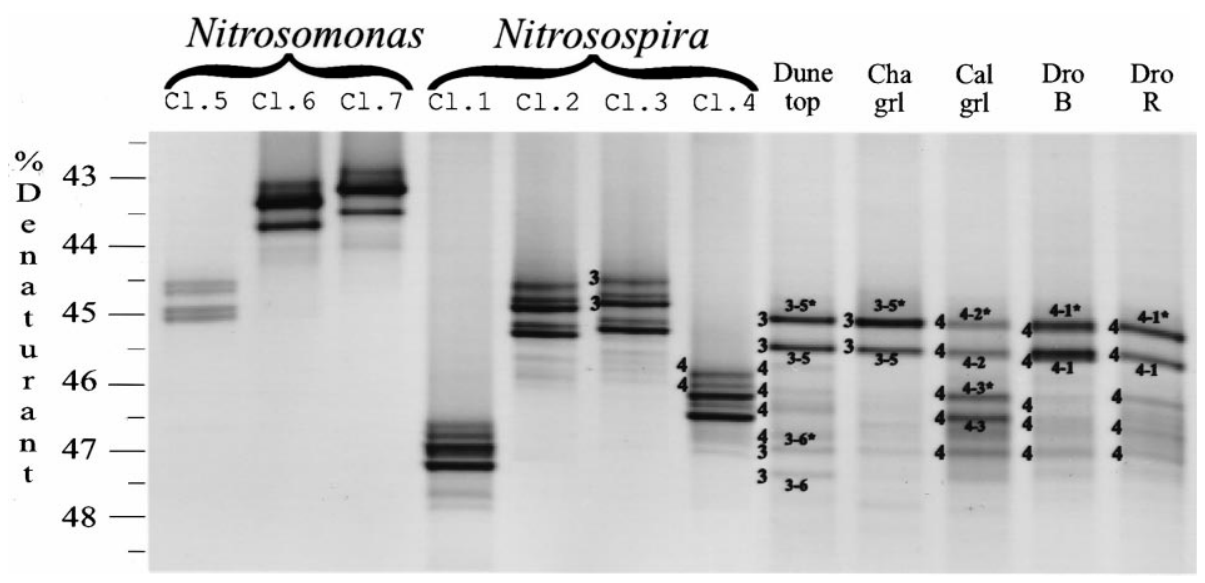

Fig. 3. DGGE of soil and sediment samples differing in oxicity. DGGE analysis of five environmental samples differing in their oxicity profiles, with the same clone references used in Fig. 2. Environmental samples are as follows: Dune top = Meijendel; Cha grl $=\mathrm{Gerendal}$; Cal grl= Brummen; Dro B=Lake Drontermeer bare sediment; Dro R= Lake Drontermeer root zone. Band labels are as described for Fig. 2. Bands from environmental samples which were too faint for identification have not been labeled.

doublets for each of the five samples which, although resolving to similar positions after DGGE, gave different cluster-specific hybridisation results. Both Drontermeer samples (different cores were used as in the analysis of the seasonal dynamics) and the Brummen calcareous grassland soil revealed a predominance of Nitrosospira cluster 4 with no detectable signal from other cluster-specific probes. The soil samples from the Gerendal chalk grassland and the Meijendel dune top contained mostly Nitrosospira cluster 3, with the latter containing faint bands which hybridised as cluster 4 Nitrosospira. These results do not reveal any clear correlation between the presence of a particular sequence cluster and the oxicity profile of the sample.

\subsection{Sequence analysis of excised bands}

In cases where bands could not be classified by hybridisation with cluster-specific probes (June 1994; root zone sample) and where hybridisation results differed from those predicted by DGGE mobility, DGGE bands were excised for DNA isolation, reamplification and sequence analysis. The bands which were sequenced have been given names in Figs. 2 and 3, and asterisks indicate a 1-bp difference introduced by the reverse primer during PCR. Identical numbers indicate identical nucleotide sequences and correspond to the numbers assigned to the ' $\mathrm{B}$ ' sequences shown in Fig. 1.

Phylogenetic analysis of the sequence derived from the DGGE doublet at $47.2 \%$ denaturant for the June 1994 root zone sample revealed that it did not show direct affinity with the monophyletic group formed by all known $\beta$-subgroup ammonia-oxidiser $16 \mathrm{~S}$ rDNA sequences (see Fig. 1). This sequence was also detected as a minor band in the July 1994 bare sediment sample. Although this sequence shows the greatest similarity with $16 \mathrm{~S}$ rDNA sequences from strains and sequences which fall within the $\beta$ subgroup ammonia-oxidiser clade (approximately $92 \%$ identity with a number of sequences), its phylogenetic position outside this group precludes the assumption that it was derived from an ammonia oxidiser. Based upon the limited phylogenetic information contained within this fragment, it is impossible to determine whether this sequence is derived from a novel group of ammonia-oxidising bacteria or if it comes from another $\beta$-subdivision Proteobacterium lacking this trait.

Where DGGE mobility and hybridisation analysis were in apparent conflict, DNA sequence analysis confirmed hybridisation results for all cases (compare named bands from Figs. 2 and 3 with phylogenetic placement in Fig. 1). This result was not unexpected, as Kowalchuk et al. [18] demonstrated 
overlapping fragment mobilities between some sequence clusters.

\section{Discussion}

\subsection{Recovery of ammonia-oxidiser $16 S \mathrm{rDNA}$ from natural samples}

The nested PCR strategy employed was successful in detecting ammonia-oxidiser $16 \mathrm{~S}$ rDNA from all soil and sediment samples tested. Previous MPN analyses of the same samples showed less than $10^{3}$ culturable ammonia-oxidising bacteria $\mathrm{g}^{-1}$ dry sediment for some samples [4]. Detection of this number of target cells in a background of at least $10^{8}$ nontarget cells compares favourably with previous attempts to detect known numbers of inoculated cells in soils [38,39]. However, as the MPN method detects only culturable cells, this may underestimate the actual number of target cells present. Unlike previous comparable studies [18,28], a nested PCR strategy was used here. Not all samples yielded PCR product after direct amplification with the CTO primers, probably due to a combination of inhibitory contaminants and low numbers of target cells. In samples for which both direct and nested PCR results could be compared, DGGE banding patterns showed only minor differences in relative band intensities (results not shown), as might be caused by random events or small differences in amplification efficiencies [40]. Furthermore, multiple DNA extractions and PCR reactions from the same core yielded reproducible banding patterns (results not shown).

\subsection{Fidelity of the CTO primers and cluster-specific oligonucleotide probes}

All PCR products recovered by the CTO primers during this study were confirmed to have originated from ammonia oxidiser-like organisms by hybridisation, save one double band found in the June 1994 root zone sample and the lowest band of the July 1994 bare sediment sample. As mentioned above, the phylogenetic placement of the sequence derived from these bands is basal to the established Nitrosomonas/ Nitrosospira radiation and, in the absence of culture data, cannot be inferred to have originated from an autotrophic ammonia oxidiser.

In all cases, phylogenetic analysis of nucleotide sequence data was in agreement with hybridisation results. As in previous studies, migration of DGGE bands with control sequences was not an accurate predictor of cluster affinity [11,28] (Fig. 1).

\subsection{G. maxima root zone vs bare sediment samples, variation in space and time}

Only Nitrosospira clusters 3 and 4 were detected in Drontermeer sediment samples. However, Nitrosomonas urea-like sequences were recovered from MPN cultures from these samples (results not shown), suggesting bias in the MPN method. DGGE has revealed the presence of similar Nitrosomonas-like sequences in soils and sediments when they have comprised as little as 5\% of the total recovered sequences ([28]; A. Speksnijder, personal communication), suggesting that Nitrosomonas-like strains comprised less than $5 \%$ of the ammonia-oxidiser population in these samples. Previous studies with specific antibodies (Bodelier, unpublished results) had detected low numbers of Nitrosomonas cells in similar Lake Drontermeer G. maxima root zone samples.

No clear population trends corresponded to the seasonal fluctuations in ammonia oxidation [4]. Although month-to-month differences were seen in the distribution of Nitrosospira sequence clusters 3 and 4, such differences appeared random (Figs. 2 and 3). Nor were consistent differences detected between root zone and bare sediment samples. The hypothesis that the balance of Nitrosospira clusters 3 and 4 is seasonally regulated in the root zone of $G$. maxima and the nearby bare sediment is not supported. Nitrifying bacteria are known to be able to survive long periods of dormancy [41,42], during which cells may show little or no activity and may exhibit a particular aversion to culturing. PCR-based techniques make no distinction between active and dormant cells, whereas MPN analyses select for easily activated cells, which may account for these differences. Detection of active ammonia-oxidiser populations might be addressed by use of reverse transcriptase PCR followed by the same DGGE and hybridisation analyses $[27,43,44]$. The use of 
functionally relevant structural gene targets, such as the genes encoding ammonia monooxygenase [45], and studies related to their expression would also be of interest in this respect.

Core-to-core variation might also complicate population distribution results. To address this issue, multiple cores (five) were examined for several sampling points. Slight differences were found between cores from a single sampling date and location (results not shown). Although the vernal peak in potential activity [4] was highly significant, some months showed high standard deviations. The most variable months with respect to activity measurements did not show the greatest core-to-core variability as detected by DGGE. As fine-scale spatial heterogeneity is important with respect to both overall microbial activity [46] and interactions with plants [47], further characterisation of core-to-core variation, combining physiological and molecular techniques, is an important topic for future study.

\subsection{Ammonia-oxidising bacteria from sediments and soils differing in oxicity profiles}

No differences in community structure could be correlated with soil/sediment oxicity for the five different Dutch locations tested (Fig. 3). Again, only Nitrosospira clusters 3 and 4 were detected. Although clear differences in the distribution of these two clusters were apparent between locations, such differences did not mirror either the oxygen kinetics of the resident ammonia-oxidising communities or oxygen availability [4]. These results do not support the hypothesis that specific sequence clusters of ammoniaoxidising bacteria are specially adapted to survival and growth under different oxygen tensions. Thus, it may be that the greater affinity for oxygen and the resistance to longer periods of anoxia displayed by sediment communities is a physiological adaptation of a generalist nitrifying community.

Given that supported sequence clusters within the $\beta$-subgroup ammonia oxidisers exist, and that some of these groups correlate with specific environments, physiological differences may underlie phylogenetic groupings $[11,18,28]$. However, it is possible that very closely related organisms might also have different physiologies, for instance in their affinity for oxygen. This is plausible considering the known varia- tion within cultured members of Nitrosospira cluster $3[15,48]$. The possibility remains that other organisms, such as nitrifiers from the $\gamma$-subgroup of the Proteobacteria or heterotrophic nitrifiers, are responsible for the seasonal fluctuations in potential ammonia-oxidising activities.

Hybridisation with specific probes has proved essential for the identification of recovered 16S rDNA fragments. The evidence presented demonstrates that Nitrosospira-like organisms related to sequence clusters 3 and 4 dominate the ammonia-oxidising community in the root zone of oxygen-releasing G. maxima stands. Low-oxygen, or periodically low-oxygen habitats, do not appear to select for a single phylogenetic cluster of ammonia-oxidising bacteria.

\section{Acknowledgments}

The authors thank Arjen Speksnijder for access to unpublished results. G.A.K was funded by a Netherlands Organisation for Pure Research grant to the Netherlands Graduate School of Functional Ecology. P.L.E.B. was sponsored by the Netherlands Foundation of Life Sciences. J.R.S. was supported both by a visitor's grant from the Royal Netherlands Academy of Arts and Sciences and by UK Natural Environmental Research Council Grant GR3/8911.

\section{References}

[1] Armstrong, W., Brändle, R. and Jackson, M.B. (1994) Mechanisms of flood tolerance in plants. Acta Bot. Neerl. 43, 307358.

[2] Blom, C.W.P.M. and Voesenek, L.A.C.J. (1996) Flooding: the survival strategies of plants. TREE 11, 290-295.

[3] Justin, S.H.F.W. and Armstrong, W. (1987) The anatomical characteristics of roots and plant response to soil flooding. New Phytol. 106, 465-495.

[4] Bodelier, P.L.E., Libochant, J.A., Blom, C.W.P.M. and Laanbroek, H.J. (1996) Dynamics of nitrification and denitrification in root-oxygenated sediments and adaptation of ammonia-oxidising bacteria to low oxygen or anoxic habitats. Appl. Environ. Microbiol. 62, 4100-4107.

[5] Both, G.J., Gerards, S. and Laanbroek, H.J. (1992) The occurrence of chemolithoautotrophic nitrifiers in water-saturated grassland soils. Microb. Ecol. 23, 15-26.

[6] Engelaar, W.H.M.G., Symens, J.C., Laanbroek, H.J. and Blom, C.W.P.M. (1995) Preservation of nitrifying capacity and nitrate availability in waterlogged soils by radial oxygen 
loss from roots of wetland plants. Biol. Fertil. Soil 20, 243248.

[7] Hansen, J.I. and Ostergaard Andersen, F. (1981) Effects of Phragmites australis roots and rhizomes on redox potentials, nitrification and bacterial numbers in the sediment. In: 9th Nordic Symposium on Sediments (Brogert, A. and Tiren, T., Eds.), pp. 72-88.

[8] Reddy, K.R., Patrick, W.H. Jr. and Lindau, C.W. (1989) Nitrification-denitrification at the plant root-sediment interface in wetlands. Limnol. Oceanogr. 34, 1004-1013.

[9] McCaig, A.E., Embley, T.M. and Prosser, J.I. (1994) Molecular analysis of enrichment cultures of marine ammonium oxidisers. FEMS Microbiol. Lett. 120, 363-368.

[10] Prosser, J.I. (1989) Autotrophic nitrification in bacteria. Adv. Microbiol. Physiol. 30, 125-181.

[11] Stephen, J.R., McCaig, A.E., Smith, Z., Prosser, J.I. and Embley, T.M. (1996) Molecular diversity of soil and marine 16S rDNA sequences related to $\beta$-subgroup ammonia-oxidising bacteria. Appl. Environ. Microbiol. 62, 4147-4154.

[12] Amann, R., Ludwig, W. and Schleifer, K.-H. (1995) Phylogenetic identification and in situ detection of individual cells without cultivation. Microbiol. Rev. 59, 143-169.

[13] Giovannoni, S.J., Britschgi, T.B., Moyer, C.L. and Field, K.G. (1990) Genetic diversity in Sargasso Sea bacterioplankton. Nature 345, 60-63.

[14] Ward, D.M., Weller, R. and Bateson, M.M. (1990) 16S rRNA sequences reveal numerous uncultured microorganisms in a natural community. Nature 345, 63-65.

[15] Head, I.M., Hiorns, W.D., Embley, T.M., McCarthy, A.J. and Saunders, J.R. (1993) The phylogeny of autotrophic ammonium-oxidizing bacteria as determined by analysis of $16 \mathrm{~S}$ ribosomal RNA gene sequences. J. Gen. Microbiol. 139, $1147-1153$.

[16] Teske, A., Elm, E., Regan, J.M., Toze, S., Rittmann, B.E. and Stahl, D.A. (1994) Evolutionary relationships among ammonia- and nitrite-oxidizing bacteria. J. Bacteriol. 176, 66236630 .

[17] Hiorns, W.D., Hastings, R.C., Head, I.M., McCarthy, A.J., Saunders, J.R., Pickup, R.W. and Hall, G. H. (1995) Amplification of $16 \mathrm{~S}$ ribosomal RNA genes of autotrophic ammonium-oxidising bacteria. Microbiology 141, 2793-2800.

[18] Kowalchuk, G.A., Stephen, J.R., De Boer, W., Prosser, J.I., Embley, T.M. and Woldendorp, J.W. (1997) Analysis of $\beta$ Proteobacteria ammonia-oxidising bacteria in coastal sand dunes using denaturing gradient gel electrophoresis and sequencing of PCR amplified 16S rDNA fragments. Appl. Environ. Microbiol. 63, 1489-1497.

[19] Voytek, M.A. and Ward, B.B. (1995) Detection of ammonium oxidising bacteria in the beta-subclass of the class Proteobacteria in aquatic samples with the PCR. Appl. Environ. Microbiol. 61, 1444-1450.

[20] Mobarry, B.K., Wagner, M., Urbain, V., Rittmann, B.E. and Stahl, D.A. (1996) Phylogenetic probes for analyzing abundance and spatial organization of nitrifying bacteria. Appl. Environ. Microbiol. 62, 2156-2162.

[21] Wagner, M., Rath, G., Amann, R., Koops, H.-P. and Schlei- fer, K.-H. (1995) In situ identification of ammonium oxidising bacteria. Syst. Appl. Microbiol. 18, 251-264.

[22] Wagner, M., Rath, G., Koops, H.-P., Flood, J. and Amann, R. (1996) In situ analysis of nitrifying bacteria in sewage treatment plants. Water Sci. Technol. 34, 237-244.

[23] Hovanec, T.A. and DeLong, E.F. (1996) Comparative analysis of nitrifying bacteria associated with freshwater and marine aquaria. Appl. Environ. Microbiol. 62, 2888-2896.

[24] Myers, R.M., Maniatis, T. and Lerman, L.S. (1987) Detection and localization of singe base changes by denaturing gradient electrophoresis. Methods Enzymol. 155, 501-527.

[25] Muyzer, G., De Waal, E.C. and Uitterlinden, A.G. (1993) Profiling complex microbial populations by denaturing gradient gel electrophoresis analysis of polymerase chain reaction-amplified genes coding for 16S rRNA. Appl. Environ. Microbiol. 59, 695-700.

[26] Muyzer, G., Teske, A., Wirsen, C.O. and Jannasch, H. W. (1995) Phylogenetic relationships of Thiomicrospira species and their identification in deep-sea hydrothermal vent samples be denaturing gradient gel electrophoresis of $16 \mathrm{~S}$ rDNA fragments. Arch. Microbiol. 164, 165-174.

[27] Teske, A., Wawer, C., Muyzer, G. and Ramsing, N.B. (1996) Distribution of sulfate-reducing bacteria in a stratified fjord (Mariager Fjord, Denmark) as evaluated by most-probablenumber counts and denaturing gradient gel electrophoresis of PCR-amplified ribosomal DNA fragments. Appl. Environ. Microbiol. 62, 1405-1415.

[28] Stephen, J.R., Kowalchuk, G.A., Bruns, M.-A., McCaig, A.E., Embley, T.M. and Prosser, J.I. (1998) Analysis of $\beta$ subgroup ammonia oxidiser populations in soil by DGGE and hierarchical phylogenetic probing. Appl. Environ. Microbiol. 64, 2958-2965.

[29] Bruns, M.A. (1996) Use of $16 \mathrm{~S}$ rDNA analysis to compare diversity of autotrophic ammonia oxidizer populations in soils. In: Nucleic Acid Analysis of Autotrophic Ammoniaoxidizing Bacteria in Soils, pp. 75-113. PhD Thesis, Michigan State University, East Lansing, MI.

[30] Edwards, U., Rogall, T., Blöcker, H., Emde, M. and Böttger, E.C. (1989) Isolation and direct complete nucleotide determination of entire genes. Characterization of a gene coding for 16S ribosomal RNA. Nucleic Acids Res. 17, 7843-7853.

[31] Sheffield, V.C., Cox, D.R. Lerman, L.S. and Myers, R.M. (1987) Attachment of a 40-base pair $\mathrm{G}+\mathrm{C}$-rich sequence (GC-clamp) to genomic DNA fragments by the polymerase chain reaction results in improved detection of single-base changes. Proc. Natl. Acad. Sci. USA, 86, 232-236.

[32] Muyzer, G., Hottentrager, S., Teske, A. and Wawer, C. (1996) Denaturing gradient gel electrophoresis of PCR-amplified 16S rDNA. A new molecular approach to analyze the genetic diversity of mixed microbial communities. In: Molecular Microbial Ecology Manual (Akkermans, A.D.I., Van Elsas, J.D. and De Bruijn, F.J., Eds.), pp. 3.4.4.1-3.4.4.22. Kluwer, Dordrecht.

[33] Gilbert, D.G. (1993) SeqApp Sequence Alignment Editor. Bloomington, Indiana. Available from the author by ftp (ftp.bio.indiana.edu). 
[34] Felsenstein, J. (1993) Phylip: Phylogeny Inference Package. Seattle, WA.

[35] Jukes, T.H. and Cantor, C.R. (1969) Evolution of protein molecules. In: Mammalian Protein Metabolism (Munro, H.N., Ed.), pp. 21-132. Academic Press, New York, NY.

[36] Saitou, N. and Nei, M. (1987) The neighbor-joining method: A new method for reconstructing phylogenetic trees. Mol. Biol. Evol. 4, 406-425.

[37] Pearson, W.R. and Lipmann, D.J. (1988) Improved tools for biological sequence analysis. Proc. Natl. Acad. Sci. USA 85, 2444-2448.

[38] DeGrange, V. and Bardin, R. (1995) Detection and counting of Nitrobacter populations in soil by PCR. Appl. Environ. Microbiol. 61, 2093-2098.

[39] Picard, C., Ponsonnet, C., Paget, E., Nesme, X. and Simonet, P. (1992) Detection and enumeration of bacteria in soil by direct DNA extraction and polymerase chain reaction. Appl. Environ. Microbiol. 58, 2717-2722.

[40] Suzuki, M.T. and Giovannoni, S.J. (1996) Bias caused by template annealing in the amplification of mixtures of $16 \mathrm{~S}$ rRNA genes by PCR. Appl. Environ. Microbiol. 62, 625-630.

[41] Jensen, K., Revsbech, N.P. and Nielsen, L.P. (1993) Microscale distribution of nitrification activity in sediment determined with a shielded microsensor for nitrate. Appl. Environ. Microbiol. 59, 3287-3296.

[42] Jones, R.D. and Morita, R.Y. (1985) Survival of a marine ammonium oxidizer under energy-source deprivation. Mar. Ecol. Prog. Ser. 26, 175-179.
[43] Felske, A., Engelen, B., Nubel, U., Backhaus, H. (1996) Direct ribosome isolation from soil to extract bacterial rRNA for community analysis. Appl. Environ. Microbiol. 62, 41624167.

[44] Wagner, R. (1994) The regulation of ribosomal RNA synthesis and bacterial cell growth. Arch. Microbiol. 161, 100-106.

[45] Rotthauwe, J.-H., Witzel, K.-P. and Liesack, W. (1997) The ammonia monooxygenase structural gene $a m o A$ as a functional marker: molecular fine-scale analysis of natural ammoniaoxidizing populations. Appl. Environ. Microbiol. 63, 4704 4712.

[46] Parkin, T.B. (1993) Spatial variability of microbial processes in soil - a review. J. Environ. Qual. 22, 409-417.

[47] Lechowicz, M.J. and Bell, G. (1991) The ecology and genetics of fitness in forest plants. II. Microspatial heterogeneity of the edaphic environment. J. Ecol. 79, 687-696.

[48] De Boer, W., Klein Gunnewiek, P.J.A. and Laanbroek, H.J. (1995) Ammonium-oxidation at low pH by a chemolithotrophic bacterium belonging to the genus Nitrosospira. Soil Biol. Biochem. 27, 127-132.

[49] Utåker, J.B., Bakken, L., Jiang, Q.Q. and Nes, I.F. (1996) Phylogenetic analysis of seven new isolates of ammonia-oxidising bacteria based on 16S rRNA gene sequences. Syst. Appl. Microbiol. 18, 549-559.

[50] Brosius, J., Dull, T.L., Sleeter, D.D. and Noller, H.F. (1981) Gene organization and primary structure of a ribosomal RNA operon from Escherichia coli. J. Mol. Biol. 148, 107-127. 